\title{
Analysis and Prediction of Cogging Torque and ripples in output Torque of Permanent Magnet Synchronous Motor and Line Start Permanent Magnet Synchronous Motor
}

\author{
Ravisankar $\mathbf{B}^{\mathrm{a}}$, Senthilnathan $\mathbf{N}^{\mathrm{b}}$, Sethupathi $\mathbf{P}^{\mathrm{c}}$ \\ ${ }^{\mathrm{a}, \mathrm{c}}$ Assistant Professor,Department of Electrical and Electronics Engineering, \\ Kongu Engineering College,Perundurai,Erode-638060 \\ ${ }^{\mathrm{b}}$ Professor,Department of Electrical and Electronics Engineering, \\ Kongu Engineering College,Perundurai,Erode-638060 \\ E-mail: ${ }^{\mathrm{a}} \mathrm{snkr86@gmail.com,}{ }^{\mathrm{b}}$ nsenthilnathan@gmail.com, ${ }^{\mathrm{c}}$ sethupk@gmail.com
}

Article History: Received: 10 November 2020; Revised 12 January 2021 Accepted: 27 January 2021; Published online: 5 April 2021

\begin{abstract}
Permanent magnet (PM) motors are rapidly replacing the squirrel cage induction motors for its energy efficient operation, smooth control and high power density. Although PM Motors are energy efficient, they are inherently affected by cogging torque and torque ripple. Magnetic alignment between teeth of stator and permanent magnet of rotors produce cogging torque. Torque ripple is a dynamic oscillation during steady-steady operation which leads to various mechanical anomalies like vibration, noise and rotor stress. Torque ripple is produced in PM motors because of non-sinusoidal distribution of flux, saturation, improper selection of slots etc., these ill effects will deteriorate the starting and steady-state performance of motors. So it is very vital to make analysis and prediction of cogging torque and torque ripples to make the motor more effective. Now a day's minimizing the torque ripples and cogging torque are gaining importance in PM motor designs. In this proposed work, the cogging torque analysis and torque ripple analysis of permanent magnet motor and line start permanent magnet motor has been done and reported.
\end{abstract}

Keywords: Finite Element Analysis (FEA), Permanent Magnet synchronous motor (PMSM), Line Start Permanent Magnet Synchronous Motor (LSPMSM)

\section{Introduction}

PM machines are gaining importance in many applications because of their high energy conversion efficiency, high power density, high energy density and low size alternative to conventional machines. The high precision drives requiring high quality of motion needs the development of PM motors with low electromagnetic cogging torque. The PM motors are having ripples in the torque which are inherent in machine. The torque ripples are parasitic in nature and they are producing noise and vibration issues in the drives. The applications like power steering, position control, robotics, and machine spindles are requiring negligible torque ripple, vibrations and noise.

Because the vibrations and the noises produced by torque ripples are deteriorating the working nature of speed control system and position control system in low speed applications [1].The rotor flux is created by group of magnets in the rotor. Each magnet is identified by thickness of magnet in radial directions, pole arc width and magnetic position within the pole pitch. The rotor is classified into many cylindrical segments each having equal length. When armature winding is fed by sinusoidal current, the cogging torque and ripples are two important contributes of pulsation in the output torque. The cogging torque is produced due to rotor tendencies to get alignment with stator at maximum permeance. The torque ripple is generated by harmonics available in the air gap flux distribution of PMs. Different studies are focusing on any one of the two contributions.

Here, in this paper the various techniques and methods are proposed for the optimization of PMSM and LSPMSM motors. These guidelines are useful for the designers to reduce torque ripple and cogging torque during design stage to achieve smoothness in developed torque.

\section{Permanent Magnet Synchronous Motor(PMSM)}

In general, solution applied to minimize the cogging torque has influence on the ripples developed by harmonics of magnetic field. So the problem of cogging torque reduction and torque ripple minimization should be taken into account as a whole. If the magnets are arranged symmetrically with the magnet width similar to pole pitch, the fundamental component of back electromotive force can reach maximum value with harmonic content causing significant torque ripples. If non symmetric arrangements of magnets are made with different magnetic width. The fundamental component of Emf reduces with variation in the harmonic content. It is important to get 
better arrangement of magnet to achieve compromise in between maximum value of fundamental component of back electro motive force and harmonic content producing ripples in the torque. Therefore, in practice, an optimization procedure has to be followed to obtain pure sinusoidal EMF waveform with negligible torque ripple.

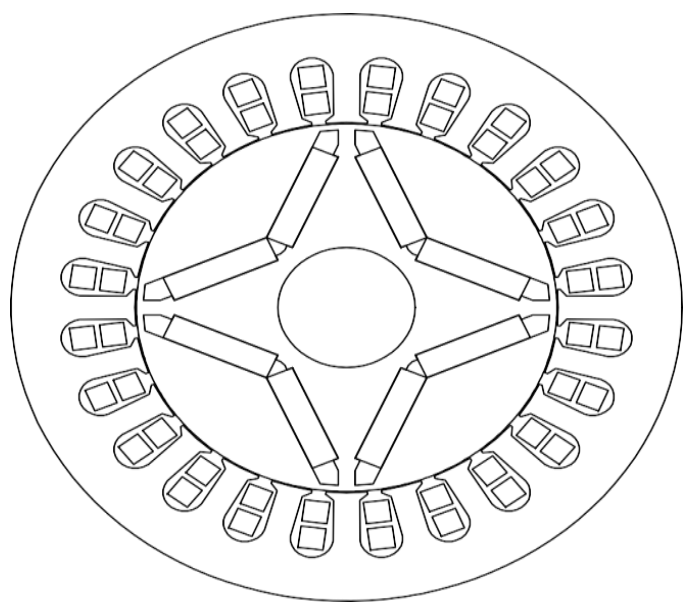

Fig.1.Cross sectional view of PMSM

Numerous methods to reduce cogging torque are employing skewing of stator teeth [2], shaping the polar piece geometry [3] and displacing the magnets, changing pole and slot number [4] optimization of magnetic pole arc to pole pitch ratio [5], employing auxiliary teeth or slots etc.

The techniques available to solve the issues of PMSM are

- One and two dimensional field analysis

- Slot less Stator

- Maxwell Stress and co energy method

- Magnetic shifting method

- Functions of flux density and permeance

- Super position method

- MMF Diagram Technique

- Synthesis of cogging torque

- Importance to concentrated windings

\subsection{One and two dimensional field analysis}

The optimization procedure should cover both the fundamental component of back electro motive force and harmonics content together without separating these two contributions. To achieve this, two step procedures to design is employed, as first step, the main design parameters are determined using global minimization algorithm having connected with analysis of one dimensional field. As second step, a 2D-FE analysis is employed to make optimization of the width of magnet arc for cogging torque minimization. If stator skewing is preferred, the complexity in machine construction increases .So to avoid that, skewed magnet segments are mounted on the rotor in which sum of magnet width is equivalent to rotor peripheral length. The polymer bonded magnetic material is molded into the rotor to avoid assembly procedures [6].

\subsection{Slot less Stator}

If slot less stator is preferred [7], the minimization of cogging torque can be done, but to reduce harmonics in sinusoidal back electromotive force, methods such as adjustment of pole arc ratio, slot/pole combinations can be used. The optimum magnet pole shape design can be used with finite element analyses to reduce harmonics content in back EMF due to capability of non linear computation. But it is time consuming. Therefore, a few hybrid model combining FEA in iron material having analytical solution for the air gap is employed without making compromise with non linear computations. But it is complicated to create direct physical interaction in 
between working performances and parameters. So the magnet pole shape deign for slot less PMSM based on Maxwell equation is preferred in which the analytical solutions for torque and back Emf are determined by using vector potential of magnet and 2D polar coordinate system without considering FE analysis. Analytical solutions of flux density because of permanent magnet (PM)and current are reached by considering (2-D) polar system and the basics of a vector potential of magnet. In particular, accurate calculation of electromagnetic torque was derived by introducing improved magnetization modelling technique which is used to solve the mathematical expressions for several circumferential thicknesses of magnet. It is concluded that the difference between the analytical calculations and FEA do not have impact on the results of the optimization. Finally the torque ripple minimization is achieved using Maxwell equations without considering time consuming FEA.

\subsection{Co energy and Maxwell Stress method}

The electromagnetic torque can be computed numerically or analytically by co energy methods and Maxwell Stress methods [8]. It needs local and global field solutions for prediction of cogging torque. The causes of slot/pole number combination on the cogging torque are examined and its link with different parameters are considered, it is possible to quantify the causes of the following design parameters:

1. pole-arc to pole-pitch ratio of magnet,

2. skewing of magnets and slots,

3. disposition of magnets,

4. slot and pole number combination considering auxiliary slots and teeth,

5. magnetization distribution, which varies from regular to trapezoidal,

6. air gap length ,slot opening width and magnet thickness.

A factor proportional to the pole/slot number and the same factor inversely proportional to least common multiple to determine the goodness of the pole/slot combinations can be introduced. Various torque calculations can be performed using virtual works and maxwell stress. The dependence upon maxwell stress path, time instant, rotor angular position, mesh can be evaluated individually [9].

\subsection{Magnetic shifting method}

Here the magnetic shifting method is considered to reduce cogging torque [10]. The magnetic shifting leads to decline in back electromotive force. To compensate that, a optimum value of pole arc to pole pitch ratio has to be selected. The proper choice of pole arc to pole pitch ratio and magnetic shifting are combined and examined using FEM. This combination involves distribution of magnet in rotor in such a manner to reduce lower order harmonics in the cogging torque.

\subsection{Functions of flux density and permeance of air gap}

Analytical prediction of cogging torque can be found using permeance function of air gap and function of flux density [11]. An unified analysis of various design techniques is employed by controlling function of flux density and function of air gap permeance. The design parameters such as teeth notching design, inter pole design, teeth width design and teeth pairing design are introduced to manage air gap permeance function. The design parameters such as interior PM design, PM shifting, magnet arc design, PM pole pairing, magnetization status design and magnet edge shaping to control are introduced for controlling flux density functions.

The pulsation of torque is directly related to square of flux density. The increased flux density can increase the cogging torque. By using functions of air gap MMF and functions of air gap permeance cogging torque has been calculated analytically. Since the width of stator tooth and stator slot are related to the cogging torque variation, the number of slots and poles are used to determine the number of tooth width having minimum cogging torque. It is revealed that the pairing of teeth with two various kinds of tooth width can suppress the cogging torque of a motor having higher slot width of stator.

\subsection{Super position method}

The super position method is used for synthesizing the resultant cogging torque waveform from the cogging torque related to leading edge and trailing edge of single stator slot [12]. The inappropriate combination of slot number and pole number may lead to high cogging torque which has to be avoided. The harmonics which are all existing in cogging torque waveform related with a single slot are not contributing to the resultant cogging torque. This method is used to access the effects of pole number and slot number combinations.

The sum of commutation torque and cogging torque gives ripples in torque. The ripple in torque can be minimized by selecting the exact value of magnet width and by shifting the pairs of pole by half the slot pitch to 
reduce the second order component in the cogging torque [13]. The validity of this technique is verified by the FE analysis of PM machines having parallely magnetized and radially magnetized PMs.

\subsection{MMF Diagram Technique}

Here, the introduction of flux-MMF diagram technique is taken into account as generalized method for prediction of cogging torque in PM machines [14].

Its main advantages are as follows:

1. It can work with various kinds of permanent magnet machines like IPMSM,SPMSM and spoke type as this technique is based on a various combinations of the characteristics of a permanent magnet and principle of virtual work,

2. It works as exact universal method to predict cogging torque and provides a fundamental base for evaluation of design.

3. It provides a clarity and graphical elucidation of cogging torque.

4. It can analyze and include many of the techniques commonly used for reducing cogging torque like varying magnet arc, bifurcated teeth, skewing and changing the magnetization of magnets.

5. It can be utilised with any level of magnetic saturation and exactness of this technique depends upon precision of estimating the dissimilarity of magnet flux at every incremental steps of rotor over a cycle of cogging torque.

This technique depends upon FEA and it is susceptible to mesh generation but it can show expected improvements in FEA. Eliminating pulsating torque by recuperating the machine design is preferable than cancelling the undesired harmonic torque components by control based techniques [15].

In applications requiring high level of torque smoothness, sinusoidal PMAC machines are preferable than the trapezoidal PMAC machines. Because design methodologies like fractional slot pitch winding, slot skewing are minimizing pulsating torque production in sinusoidal PMAC machines and minimization pulsating torque leads to trade off between ripple torque and cogging torque production and trapezoidal PMAC motor is subjected to commutation torque dips and spikes. So it requires extra sensor to solve it. The control based techniques needs active cancellation methods which requires accurate information of machine parameters given by adaptive control.

\subsection{Synthesis of cogging torque}

Analytical technique to synthesis the waveform of cogging torque related with a single stator slot is proposed by applying to two motors with fractional number of pole/slot and it is revealed that all harmonics related with cogging torque because of single slots are not present in resulting cogging torque [16]

\subsection{Importance to concentrated windings}

The increased amount of effects like alternating magnetic field, magnetic noise, unbalanced radial forces are making manufacturers to prefer PM with concentrated winding instead of distributed windings[17].

Table 1.Summary of Issues and Technique used for PMSM.

\begin{tabular}{clcc}
\hline \hline $\begin{array}{c}\text { Motor } \\
\text { types }\end{array}$ & ISSUES & TECHNIQUE USED & PERFORMANCE \\
\hline PMSM & Torque ripples & $\begin{array}{c}\text { One dimensional field } \\
\text { analysis with multi objective } \\
\text { minimization techniques }\end{array}$ & Torque ripples reduced. \\
& $\begin{array}{l}\text { Optimizing the magnet arc } \\
\text { width using two dimensional } \\
\text { model[6] }\end{array}$
\end{tabular}


PMSM Interaction of harmonics of same number from magnetic field and permeance.

Interaction of mixed harmonics from the magnetic field produced by the stator slotting and permeance harmonics.

PMSM Torque ripple

PMSM Quantifying effects on cogging torque

PMSM Cogging torque

PMSM

Cogging torque

PMSM

Cogging torque

PMSM
Fractional slot winding[7]

Construction of the stator slot zone geometry is preferred to minimize cogging torque.
Analytical method based on Maxwell equation [8].

A factor is introduced for selection of slots and teeth.

Magnetic shifting method [10].

Air gap permeance function flux density functions [11].

Air gap MMF function and air gap permeance function[14]
A flux density calculation based optimization achieved through by an analytical method is found to be best for torque minimization.

Lower the value of factor lower the cogging torque.

Reduced lower order harmonics in the cogging torque.

\section{Cogging torque reduced}

\section{Cogging torque suppressed}

Synthesis of cogging torque is done.

\section{Line Start Permanent Magnet Synchronous Motor}

The LSPMSM can be operated directly from power supply without using inverter and rotor position sensors. The LSPMSM has been considered as the suitable alternative for IM due to its highest efficiency, self-starting and no copper loss at rotor while running at synchronous speed [18]. LSPMSM combines the torque characteristics of both PMSM and IM. Few low levels industrial three phase IMs are being affected from poor power factor and poor operational efficiency. Now days the performance of materials of PM have been highly enhanced and their price are falling. Thus, LSPMSM are gradually being used in various industrial applications for their high efficiency, high power factor and high power density. The Induction motor has advantages of robust construction and line starting capability but having disadvantages of low power factor, low efficiency and low slip losses.

The traditional synchronous motor otherwise known as doubly fed AC motor running at synchronous speed is having limitations of additional DC power source, tear and wear due to presence of assemblies of brush gear and commutators. But PMSM excludes the usages of DC power source, commutators and brushes.

The conventional synchronous motors need a DC rotor field excitation. But PM synchronous machine uses a permanent magnet to generate rotor flux. The PMSM has advantages of high power factor, high values of torque 
per unit current density and high efficiency when compared to induction motors with same rated power. The LSPMSM unites the advantages of both induction motors and the usual PMSM.

Torque smoothness is a vital requirement in a many motion control application. For example, the smoothness of the instantaneous torque provided to rotary tool piece in metal working tools is providing quality in surface finish. Similarly, many applications expect high levels of torque smoothness to achieve user expectations. LSPMSM's torque slip characteristics in the asynchronous operating region is poorer than the torque slip characteristics of a IM with the identical squirrel cage design, stator winding design, materials and geometry of stator and rotor slots.

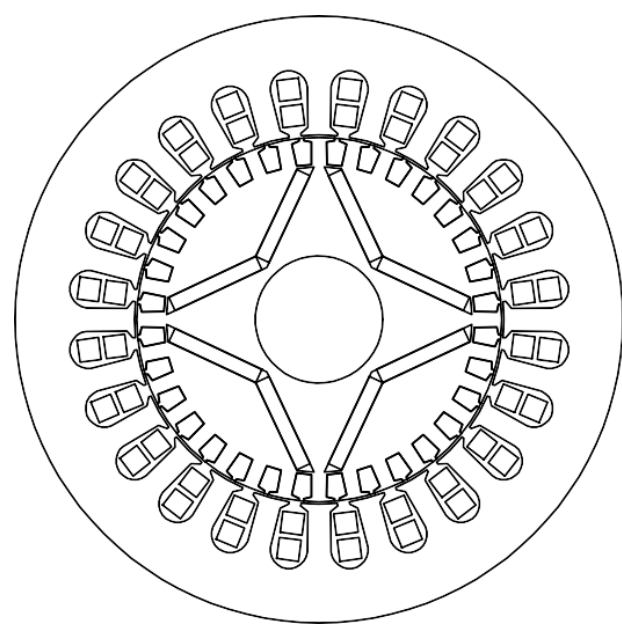

Fig.1.Cross-Sectional View of LSPMSM

When LSPMSM is line started, the permanent magnet introduces a braking torque which reduces the total torque and the rotor saliencies introduce a reluctance torque which also further reduces the total torque.

Parasitic torques produced by the iron core saturation, variation in reluctance of the air gap due to rotor and stator slotting and concentration of winding into slots reduces the total torque in the asynchronous region of LSPMSM. Parasitic torque is considered as dip in torque-slip characteristics of induction motor. This parasitic torque arises from the harmonic component and fundamental component of air flux density because of consideration of geometrical parameters like saturation effects and slotting effects.

Cogging torque is the one of the pulsating torque components produced by the interaction of the flux in the rotor and angular variation in the reluctance of the stator. Mutual or alignment torque is the one of the pulsating torque components resulting from the interaction of the current mmf of stator with flux distribution of rotor magnet. This is the leading torque production mechanism. Reluctance torque is the one of the pulsating torque components being produced from the interaction of current mmf's of the stator with the angular variation of magnetic reluctance of the rotor. Pulsating torque=cogging torque+ripple torque component.

The techniques used to solve the issues of LSPMSM are

- Pole changing technique.

- New analytical method for reducing air gap flux distribution.

- Magnetic circuit analysis.

- Enhancing self starting capability

- Preisach's modelling

- Usage of MATLAB functions and flux barriers

- dq models

- Transient torque analysis

- Usage of simulink models

- Compromises in the design 


\subsection{Pole changing Technique}

The perfection in steady state performance can be achieved by improving the strength of permanent magnet. The increase in PM strength can produce braking torque that results with low starting torque. Braking torque is reducing starting torque of LSPMSM motor. The increase in the strength of PM is improving the synchronizing capability of the motor. So trade off has to be maintained in between both high starting torque and good synchronizing capability. The increase in cage resistance is giving good starting torque but it is reducing the synchronizing capability of the motor. So to achieve good synchronizing capability, there is need for increasing strength of PM. To overcome the braking torque produced by PM, pole changing method can be approached instead of preferring reduction of cage resistance which lowers starting torque. By selecting required winding connections at starting period, braking torque can be reduced to minimum to achieve high starting torque. A method to overcome the disadvantages of braking torque, synchronization problems, low starting torque, pulsating torque, dominance of braking torque during starting period is proposed.

In this method, the motor is started with less number of poles and no of poles are increased when speed reaches synchronous speed [19].

The best schemes proposed for pole changing are as follows:

1. Starts with delta connections and enter into steady state mode with star connections,

2. Starts with parallel star connection in asynchronous state and reaches steady-state with delta series connection in synchronous state,

3. Starts with parallel connection and reaches steady-state mode with series connection.

Finally, it is concluded that braking torque is reduced to improve the starting torque by proper usage of suitable arrangements of winding in the asynchronous state. The proposed method was validated by performing simulation from 2-D FEM package software.

\subsection{New analytical method for reducing air gap flux distribution.}

When compared to other PM motors, LSPMSM [20] is having some additional features like two sided slots on its rotor and stator. Because of two sided slots on both rotor and stator, LSPMSM is having complex air gap form. So it is difficult to perform analysis of cogging torque. The air gap of LSPMSM is classified into rotor side and stator side and the effective air gap length expression is derived by applying superposition considering relative position angle between air gap of rotor side and stator side. Thus the complexity of the length of air gap expression results with complexity in the analysis of the cogging torque in LSPLSM. So a new analysis of cogging torque based on analytical method which considers the rotor as corresponding magneto motive force distribution of the air gap is preferred. In this new analysis of cogging torque expression, the expression for effective length of air gap on the stator side is only considered avoiding the calculation of the expression for effective air gap length on the rotor side to calculate the effect of stator slot skew and slot pole combinations.

In this way, the effective length of air gap is related only to the stator, avoiding the difficulty in calculating the effective length of air gap that needs to include rotor slotting. Thereafter, the influences of pole-slot combinations and stator slot skew on cogging torque are analyzed, and the validity of the analysis is verified by FEM.

A design process considering starting torque and efficiency is preferred in which equivalent circuit was used for design of permanent magnets and cage and FEM was used for design of barriers. The weight function of taguchi simulation has been used for consideration of starting torque and efficiency. Finally, the characteristic of proposed best model was compared to conventional induction motor of same rated power to verify the validation of optimal model. Initially, in the conventional theory, the performance of torque at asynchronous start is examined without considering effects of coupling in between magnetic fields produced by cage bar current and PMs. Then, by using torque separation method, PM braking torque and cage torque are calculated independently in view of a pure PM motor and a pure IM. This torque separation method does not give any theoretical background of oscillating frequency from the conventional approach.

Finally in the modified theory, by considering mutual effect in between magnetic fields of cage bar current and PMs. Asynchronous torque characteristics of modified theory is compared with that of torque separation method and revealed that two principal oscillating components of cage torque of a LSPMPM motor are available[21]. One is component with the dual slip frequency because of variation in reluctance during rotation, and another one is component with the slip frequency because of saturation in magnets. The changes in the reluctance produced by the salient geometry of rotor produce not only the reluctance torque but also asynchronous torque that varies with the dual slip frequency in the asynchronous region of operation. These types of oscillations are taking place in usual synchronous reluctance motors. The saturation in the magnet, which is consistently 
produced by flux of PM, creates variations in another collateral reluctance, which causes variation with the slip frequency. Note that this pulsation occurs only in line-start PM motors. Furthermore, the effect of coupling in between the flux of PM and flux of the cage-bar causing larger oscillations has been revealed in this study [22].

\subsection{Magnetic circuit analysis.}

The magnetic equivalent circuit is used to design various models by changing geometrical component such as angle of magnetic poles, radius of magnetic pole to get desired torque. The main design parameters considered are insert angle, thickness, rotor bar resistance and insertion position [23].

\subsection{Enhancing self starting capability}

To enhance starting torque, the effect of no load characteristics, effect of pole width of rotor, effect of saliency depth ratio, effect of distance in between the stator poles extremities are analysed [24].

\subsection{Preisach's modelling}

Here, preference to $\mathrm{M}-\mathrm{H}$ relation is given when compared to $\mathrm{BH}$ relation. For rotating machines, preisach model is considered as scalar model in which $\mathrm{M}$ and $\mathrm{H}$ are having same vector direction. The Everett integrals are used for convenience in which $\mathrm{H}$ distribution is having gaussian ones. Finally it is revealed that torque output using preisach modelling is less significant than torque output in traditional $\mathrm{BH}$ modelling and this modelling gives reasonable value for hysteresis loss [25].

\subsection{Usage of MATLAB functions and flux barriers}

The starting characteristics of asynchronous region and torque capabilities of synchronous region revealed by MATLAB functions are validated by analysis method based on simplified dq model and mathematical model and constant speed of motor is ensured even during variation in loads. The existence of short circuiting flux due to PM decrease the steady state and starting performance of motor by undergoing reduction in flux density of air gap. This can be overcomed by designing the rotor with high reluctance flux barriers [26].

\section{7 dq models}

The dq model to analyse synchronous capability is proposed with FEM to predict transient and dynamic performance, speed curve, starting current and efficiency etc. By using dq model, the rotor bar with lower demagnetisation of PM is designed for pumping systems [27].

\subsection{Transient torque analysis}

Based on this torque analysis method of resolving starting torque, the electromagnetic torque is classified into driving torque component and braking torque component considering iron saturations. The validity of starting torque calculated using analysis method is proved by time stepping FEM techniques. By using this method, knowledge about synchronization mechanism can be obtained [28].

\subsection{Usage of Simulink model}

To analyse the effects of voltage on electromagnetic torque, speed, slip and armature current, the LSPMSM is designed with arc straight PM.The validity of this LSPMSM is proved by establishing simulink mode with consideration of motion equation and voltage equations [29].

\subsection{Compromises in design}

The analytical design methods taking into account of operation point in BH curve and taking into account of synchronous and asynchronous performance are proposed to operate LSPMSM at unity power factor.

While designing LSPMSM, a designer has to undergo various compromises in the process.

- The compromise has to be made in between starting current, material and starting torque.

- The compromise has to be made in between PM's energy product and PM's braking torque, which has significant effect on synchronous capability of motors.

- The compromise has to be made in between synchronous region and asynchronous region [30]. 
Table 2. Summary of Issues and Technique used for LSPMSM

\begin{tabular}{|c|c|c|c|}
\hline $\begin{array}{l}\text { Motor } \\
\text { types }\end{array}$ & ISSUES & TECHNIQUE USED & PERFORMANCE \\
\hline LSPMSM & $\begin{array}{lr}\text { Braking } & \text { torque, } \\
\text { synchronization } & \text { problems, } \\
\text { low starting } & \text { torque, } \\
\text { pulsating } & \text { torque, } \\
\text { dominance of } & \text { braking } \\
\text { torque during } & \text { starting } \\
\text { period. } & \end{array}$ & pole changing[19]. & $\begin{array}{l}\text { braking torque is reduced to } \\
\text { improve the starting torque }\end{array}$ \\
\hline LSPMSM & cogging torque & $\begin{array}{l}\text { To model the rotor as } \mathrm{MMF} \\
\text { distribution in air gap[20]. }\end{array}$ & $\begin{array}{l}\text { effect of reduction in cogging } \\
\text { torque is realized }\end{array}$ \\
\hline LSPMSM & $\begin{array}{l}\text { design process considering } \\
\text { starting torque and } \\
\text { efficiency }\end{array}$ & $\begin{array}{l}\text { Weight function of taguchi } \\
\text { simulation is used [21]. }\end{array}$ & $\begin{array}{l}\text { Characteristic of proposed } \\
\text { optimal model is validated by } \\
\text { experimental one. }\end{array}$ \\
\hline LSPMSM & $\begin{array}{l}\text { occurrence of torque } \\
\text { pulsation }\end{array}$ & $\begin{array}{l}\text { The proposed analytical } \\
\text { approach and modified theory } \\
{[22] \text {. }}\end{array}$ & $\begin{array}{l}\text { the coupling effect in between the } \\
\text { cage-bar flux and the PM flux } \\
\text { causing higher oscillations has } \\
\text { been revealed }\end{array}$ \\
\hline LSPMSM & short circuiting flux & $\begin{array}{l}\text { Designing rotor with high } \\
\text { reluctance flux barriers[26] }\end{array}$ & $\begin{array}{l}\text { steady state and starting } \\
\text { performance has been improved }\end{array}$ \\
\hline LSPMSM & demagnetization & dq model[27] & $\begin{array}{l}\text { used to predict transient and } \\
\text { dynamic performance. }\end{array}$ \\
\hline
\end{tabular}

\section{Conclusion}

This study explains the various methods of prediction and analyzes for determining torque ripples in PM motors and LSPMSM. Some guidelines are important for minimization of ripples in torque and cogging torque of PM and LSPMSM to satisfy needs of the load. Magnetic shifting method and Superposition methods PMSM are found to be effective in controlling cogging torque. The pole changing technique in LSPMSM is found to be best in controlling torque ripples. There are tradeoffs between torque ripple, cogging torque, magnet volume and efficiency of both motors. Based on these design methodologies, designer can select suitable rotor configurations and magnet volume to get optimum performance in these motors

\section{References}

Borghi C A,Casadei D, Cristofolini A, Fabbri M and Serra G 2002 Minimizing torque ripple in permanent magnet synchronous motors with polymer-bonded magnets IEEE Transactions on Magnetics 38 1371-1377.

Touzhu Li and Slemon G 1988 Reduction of cogging torque in permanent magnet motors IEEE Transactions on Magnetics 24 2901-2903.

Braga Filho E R,Lima A M N and Araujo T S 1998 Reducing cogging torque in interior permanent magnet machines without skewing IEEE Transactions on Magnetics 34 3652-3655.

D.Sc. Pia Salminen and Juha Pyrhöne 2005 Torque Ripple Of Permanent Magnet Machines With Concentrated Windings XII International Symposium on Electromagnetic Fields in Mechatronics, Electrical and Electronic Engineering Baiona 15-17.

Schlensok C,Gracia M H and Hameyer K 2006 Combined numerical and analytical method for geometry optimization of a PM motor IEEE Transactions on Magnetics 42 1211-1214.

Pristup A G, Toporkov D M \& Shevchenko A F 2014 A study of cogging torque in permanent magnet synchronous machines with fractional slot windings. Russ. Electr. Engin. 85 743-747.

Jang S,Park H,Choi J, Ko K and Lee S 2011 Magnet Pole Shape Design of Permanent Magnet Machine for Minimization of Torque Ripple Based on Electromagnetic Field Theory IEEE Transactions on Magnetics 47 3586-3589. 
Zhu Z Q and Howe D 2000 Influence of design parameters on cogging torque in permanent magnet machines IEEE Transactions on Energy Conversion 15 407-412.

Salon S, Bhatia S and Burow D 1997 Some aspects of torque calculations in electrical machines," in IEEE Transactions on Magnetics 33 2018-2021.

Dosiek L and Pillay P 2007 Cogging Torque Reduction in Permanent Magnet Machines IEEE Transactions on Industry Applications 43 1565-1571.

Sang-Moon Hwang, Jae-Boo Eom, Yoong-Ho Jung, Deug-Woo Lee and Beom-Soo Kang, 2001 Various design techniques to reduce cogging torque by controlling energy variation in permanent magnet motors IEEE Transactions on Magnetics 37 2806-2809.

Zhu Z Q, Ruangsinchaiwanich S, Chen Y and Howe D 2006 Evaluation of superposition technique for calculating cogging torque in permanent-magnet brushless machines IEEE Transactions on Magnetics vol. 42 1597-1603.

T. Ishikawa T and G. R. Slemon G R 1993 A method of reducing ripple torque in permanent magnet motors without skewing IEEE Transactions on Magnetics 29 2028-2031.

Deodhar R P,Staton D A,Jahns T M and Miller T J E 1996 Prediction of cogging torque using the flux-MMF diagram technique IEEE Transactions on Industry Applications 32 569-576.

Jahns T M and Soong W L 1996 Pulsating torque minimization techniques for permanent magnet AC motordrives-a review IEEE Transactions on Industrial Electronics 43 321-330.

Zhu Z Q, Ruangsinchaiwanich S and Howe D 2006 Synthesis of cogging-torque waveform from analysis of a single stator slot IEEE Transactions on Industry Applications 42 650-657.

Magnussen F and Lendenmann H 2007 Parasitic Effects in PM Machines With Concentrated Windings IEEE Transactions on Industry Applications 43 1223-1232.

Sethupathi P and Senthilnathan N 2020 Comparative analysis of line-start permanent magnet synchronous motor and squirrel cage induction motor under customary power quality indices. Electr Eng 102 1339-1349.

Damaki Aliabad A,Mirsalim M and Farrokhzad Ershad N 2010 Line-Start Permanent-Magnet Motors: Significant Improvements in Starting Torque, Synchronization, and Steady-State Performance IEEE Transactions on Magnetics 46 4066-4072.

Jing L, Gong J, and Lin Y 2019 Analysis and Reduction of Cogging Torque of Line-Start Permanent Magnet Motors Progress In Electromagnetics Research M 78 115-124.

W. Kim et al 2009 A Study on the Optimal Rotor Design of LSPM Considering the Starting Torque and Efficiency IEEE Transactions on Magnetics 45 1808-1811.

Takahashi, Akeshi \& Kikuchi, Satoshi \& Miyata, Kenji \& Binder, Andreas 2014 Asynchronous Torque of LineStarting Permanent-Magnet Synchronous Motors IEEE Transactions on Energy Conversion 30 1-9.

D. Jung et al 2007 A Study on the Design and the Characteristics in Single-Phase Line-Start Permanent Magnet Motor 2007 International Conference on Electrical Machines and Systems (ICEMS) Seoul 878-881.

ensaida K, Abdennadher I,Masmoudi A and Marignetti F 2018 On the enhancement of the starting capabilities of single phase line-start PMSMs 2018 Thirteenth International Conference on Ecological Vehicles and Renewable Energies (EVER) Monte-Carlo 1-6.

Sol Kim, Jung-Ho Lee and Ju Lee 2003 A study on hysteresis analysis of line start permanent magnet motor using Preisach modeling IEEE Transactions on Magnetics 39 2543-2545.

Bala M J,Deb N K and Chowdhury S K 2017 Improvement of the performances of line start permanent magnet synchronous motor with flux barrier in the rotor 2017 IEEE Calcutta Conference (CALCON) Kolkata 357361.

Jian Li, Jungtae Song and Yunhyun Cho 2010 High performance line start permanent magnet synchronous motor for pumping system 2010 IEEE International Symposium on Industrial Electronics Bari 1308-1313.

Akeshi Takahashi et al 2008 Transient-torque analysis for line-starting permanent-magnet synchronous motors 2008 18th International Conference on Electrical Machines Vilamoura 1-6.

$\mathrm{Xu}$, Xiao Zhuo, et al 2013 Starting Performance Analysis of Line-Start Permanent Magnet Synchronous Motor with Novel Rotor Structure Applied Mechanics and Materials 273 291-295.

Stoia, Dan \& Cernat, Mihai \& Jimoh, Abdul-Ganiyu \& Nicolae D V 2009 Analytical design and analysis of Line-Start Permanent Magnet Synchronous Motors IEEE AFRICON Conference 1 - 7. 